\title{
Binder design of high RAP content hot and warm asphalt mixture wearing courses
}

Article in Road Materials and Pavement Design · April 2015

DOI: $10.1080 / 14680629.2015 .1029707$

CITATIONS

2

\section{3 authors:}

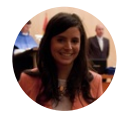

Ana Jiménez del Barco Carrión

University of Nottingham

7 PUBLICATIONS 3 CITATIONS

SEE PROFILE

\section{Gordon D. Airey}

University of Nottingham

179 PUBLICATIONS 1,962 CITATIONS

SEE PROFILE

Some of the authors of this publication are also working on these related projects:

SUSTAINABLE RAILWAYS: Maximising recycling by minimising the impact on people and planet View

Project project

SUSTAINABLE PAVEMENTS - maximising recycling by minimising the impact on the people and planet 


\title{
Binder design of high RAP content hot and warm asphalt mixture wearing courses
}

\author{
A. Jiménez del Barco Carrión*, D. Lo Presti*, G.Airey*
}

To cite this article:

Jiménez del Barco Carrión, D. Lo Presti \& G.D. Airey (2015): Binder design of high RAP content hot and warm asphalt mixture wearing courses, Road Materials and Pavement Design, DOI: 10.1080/14680629.2015.1029707

To link to this article: http://dx.doi.org/10.1080/14680629.2015.1029707

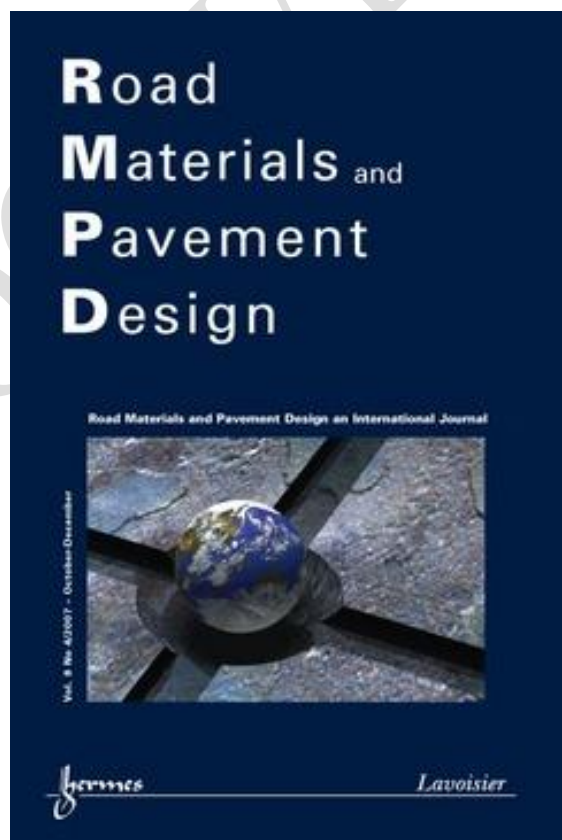




\title{
Binder design of high RAP content hot and warm asphalt mixture wearing courses
}

\author{
A. Jiménez del Barco Carrión*, D. Lo Presti*, G.Airey*
}

\section{*University of Nottingham}

Pavement Research Building, University Park, NG7 2RD, UK

ana.jimenezdelbarcocarrion@nottingham.ac.uk

davide.lopresti@nottingham.ac.uk

gordon.airey@nottingham.ac.uk

\begin{abstract}
Reclaimed Asphalt Pavement (RAP) has shown great potential for being used in the construction or maintenance of roads. However, RAP is usually downgraded to lower pavement layers and the percentage of RAP used in wearing courses is still moderate ( $\leq$ $30 \%$ ). The research and results contained in this paper focus on the definition of binder recipes aimed at increasing the percentage of RAP in Hot and Warm Mix Asphalt wearing courses. A review of current internationally used blend design methodologies is presented followed by case studies aimed at defining binder recipes for high RAP content asphalt mixture wearing courses to be further used for mix design and production in asphalt plants. Binder design has been carried out by means of rotational viscosity, DSR, BBR and conventional experimental tests with results showing that the amount of RAP used in a mix can be increased through the development of an accurate binder design and the selection of an appropriate rejuvenator. As a result, laboratory design showed that using up to $90 \%$ of RAP is a feasible option. However, the percentage of RAP to be used is highly dependent on the properties of the initial RAP binder, so every case has to be independently and carefully studied. The research presented is carried out as part of the CEDR Transnational Road research Programme Call 2012 (http://allback2pave.fehrl.org) and the Marie Curie Initial Training Network (ITN) action, FP7-PEOPLE-2013-ITN (http://www.superitn.eu).
\end{abstract}




\section{Introduction}

The re-use of Reclaimed Asphalt Pavement (usually known as RAP) in new asphalt mixtures is mainly promoted for two reasons: environmental sustainability and economic benefits. Therefore, over the last decades, considerable research effort has focused on increasing the percentage of RAP in asphalt mixtures showing promising results (Hajj et al. 2009; McDaniel et al. 2012; Tran et al. 2012; Visintine et al. 2013). However, RAP use is still downgraded in other layers rather than replacing it within wearing courses. When RAP was used in wearing courses, high content RAP mixtures were identified as having more that 25\% RAP with this limit usually not exceeding the maximum allowed RAP content by road authorities/state agencies, which typically is not more than $40 \%$ (Mollenhauer 2010). This research, however, focuses on defining techniques for restoring the properties of the RAP aged binders, in order to raise the bar in asphalt recycling to design asphalt mixtures for wearing courses with RAP contents as close as possible to $100 \%$. Other studies have proven that the realization of such mixtures is technically feasible by using rejuvenators (Dony et al. 2013; Zaumanis et al. 2013; Zaumanis et al. 2014) and with the support of tailored experimental techniques to predict the properties of the final binder and relative mixtures.

Among these techniques, blending laws to predict the properties of the final binder, composed of aged binder from RAP and rejuvenators (i.e. bitumen, additives, organic oils, etc.), are an essential requirement before any mix design can be undertaken. Because of the presence of stiffer (aged) binders, high RAP content mixes are perceived to be more susceptible to damage, such as fatigue and thermal cracking, than mixes with virgin binders. Rejuvenation of aged binders helps in this sense but an appropriate dosage of a compatible rejuvenator is necessary to prevent an increase in the susceptibility of the asphalt mixture to rutting and to ensure mixture longevity. Indeed, if an appropriate amount of rejuvenator is added and properly mixed, the recycled RAP binder obtained could improve cracking resistance of the asphalt mixture without adversely affecting its resistance to rutting, providing even better performance than with the use of softer binders (Shen et al. 2007; Tran et al. 2012).

In order to engineer this process, most countries have developed their own blending models: European countries use empirical properties to design blends, while USA uses performance-related properties and Australian models are based on viscosity. This paper describes a research study which aims at performing a preliminary binder blend design to establish quality and proportions of rejuvenators to be used with the selected RAP. This is achieved by performing the mix design of a typical asphalt mix for wearing courses, incorporating several percentages of RAP (up to $90 \%$ in total weight of mix) as well as the use of a warm mix technology. The study undertakes and compares three models (EU, US and AUS) by taking into account the addition of rejuvenators that could improve RAP binder properties and, in this way, allow increased percentages of RAP in the mix. For this purpose, blend design was carried out taking into account the Rejuvenated RAP binder and virgin binder and the concepts of full and partial blending and Replaced Virgin Binder (RVB). 


\section{Background: Review of blending laws for RAP mixes}

Given that RAP comes from the recovery of pavements that have been in service, considerations about its properties have to be taken into account. Therefore, in order to be re-used, RAP is usually required to meet some specifications depending on the country in which it will be used. In order to meet these specifications and when the desired percentage of RAP in the mix is high, blending models for the RAP binder and the virgin binder have to be used to design the final content of RAP or to design a final binder with certain desired properties. Mollenhauer (2010) provides an excellent summary of the different approaches used for the blend design of RAP binders from all over the world. This following section provides a summary of the three most commonly used methodologies found in literature:

\section{EU methodology:}

European blending models are based on the penetration and softening point properties of the RAP recovered binder and the virgin binder. European Standard EN 13108-8:2005 for reclaimed asphalt sets out that the binder class of the virgin binder may be used unaltered if the mix design includes less than $10 \%$ RAP for surfacing layers and less than 20\% RAP for base layers and binder courses. If higher proportions of RAP are used, the penetration and softening point values of the binder blend are to be determined using Equations 1 and 2 respectively: where

$$
a \log p e n_{1}+b \log p e n_{2}=(a+b) \log p e n_{\text {mix }}
$$

pen $_{1}=$ penetration of the binder recovered from the RAP

pen $_{2}=$ penetration of the added virgin binder

pen $_{\text {mix }}=$ calculated penetration value of the binder in the mixture containing RAP $a, b=$ ratios by mass of the binder from the RAP and of the virgin binder respectively $(\mathrm{a}+\mathrm{b}=1.0)$

$$
T_{R \& B \text { mix }}=a T_{R \& B 1}+b T_{R \& B 2}
$$

$T_{R \& B 1}=$ softening point of the binder recovered from the RAP

$T_{R \& B 2}=$ softening point of the added virgin binder

$T_{R \& B}$ mix $=$ softening point of the binder in the mixture containing RAP

$a, b=$ ratios by mass of the binder from the RAP and of the virgin binder respectively $(\mathrm{a}+\mathrm{b}=1.0)$

\section{USA methodology:}

NCHRP Report 452 (2001) specifies that for low RAP contents $(10-20 \%)$, it is not necessary to do tests because there is not enough of the old, hardened RAP binder present in the mix to change the total binder properties. At higher RAP contents, however, the RAP binder will have a noticeable effect, and it must be accounted for by using a softer grade of virgin binder. For intermediate ranges of 
RAP, the virgin binder grade can simply be dropped one grade. However, for higher percentages of RAP, RAP binder has to be recovered and blend design has to be carried out. NCHRP Report 452 (2001) describes the procedure to obtain blending charts according to SUPERPAVE. This procedure is based on critical temperatures of materials and follows the prediction law (Equation 3):

$$
\mathrm{T}_{\text {blend }}=\mathrm{T}_{\mathrm{RAP}} * \% \mathrm{RAP}+\mathrm{T}_{\mathrm{VB}} * \% \mathrm{VB}
$$

where,

$\mathrm{T}_{\text {blend }}=$ critical temperature of the final blend of binders

$\mathrm{T}_{\mathrm{RAP}}=$ critical temperature of the RAP binder

$\mathrm{T}_{\mathrm{VB}}=$ critical temperature of the virgin binder used as rejuvenator

$\% \mathrm{RAP}=$ percentage of RAP

$\% \mathrm{VB}=$ percentage of virgin binder in the blend

Therefore, in order to construct blending charts, critical temperatures of the RAP recovered binder have to be known. Thus, once the RAP binder has been recovered, its properties have to be determined by undertaking DSR and BBR tests. Firstly, RAP binder has to be tested on the DSR at high temperatures. Then, RAP binder has to be aged through the RTFO test procedure and tested on the DSR at high and intermediate temperatures and on the BBR at low temperatures. With the results of these tests, critical temperatures can be determined as follows:

1. High critical temperature $\left(\mathrm{T}_{\mathrm{c}}(\mathrm{High})\right)$. The slope of the stiffness-temperature curve of the unaged RAP binder is determined as $\Delta \log \left(\mathrm{G}^{*} / \sin \delta\right) / \Delta \mathrm{T}$ and Equation 4 is used:

$$
\mathrm{T}_{\mathrm{C}}(\text { High })_{1}=\left(\frac{\log (1.00)-\log \left(\mathrm{G}_{1}\right)}{\mathrm{a}}\right)+\mathrm{T}_{1}
$$

where,

$G_{1}=$ the $\mathrm{G}^{*} / \sin \delta$ value in $\mathrm{kPa}$ at a specific temperature $\mathrm{T}_{1}$

$\mathrm{a}=$ the slope of the stiffness-temperature curve determined as $\Delta \log \left(\mathrm{G}^{*} / \sin \delta\right) / \Delta \mathrm{T}$

The slope of the stiffness-temperature curve of the RTFOT RAP binder is determined as $\Delta \log \left(\mathrm{G}^{*} / \sin \delta\right) / \Delta \mathrm{T}$ and Equation 5 is used:

$$
\mathrm{T}_{\mathrm{C}}(\text { High })_{2}=\left(\frac{\log (2.2)-\log \left(\mathrm{G}_{1}\right)}{\mathrm{a}}\right)+\mathrm{T}_{1}
$$

where,

$\mathrm{G}_{1}=$ the $\mathrm{G}^{*} / \sin \delta$ value in $\mathrm{kPa}$ at a specific temperature $\mathrm{T}_{1}$ $\mathrm{a}=$ the slope of the stiffness-temperature determined as $\Delta \log \left(\mathrm{G}^{*} / \sin \delta\right) / \Delta \mathrm{T}$

$\mathrm{T}_{\mathrm{C}}($ High $)$ is chosen between $\mathrm{T}_{\mathrm{C}}(\mathrm{High})_{1}$ and $\mathrm{T}_{\mathrm{C}}(\mathrm{High})_{2}$ as the most restrictive value (the lower one). 
2. Intermediate critical temperature (Tc(Int)). The slope of the stiffness-temperature curve of the RTFOT RAP binder is determined as $\Delta \log \left(\mathrm{G}^{*} / \sin \delta\right) / \Delta \mathrm{T}$ and Equation 6 is used:

$\mathrm{T}_{\mathrm{C}}($ Int $)=\left(\frac{\log (5000)-\log \left(\mathrm{G}_{1}\right)}{\mathrm{a}}\right)+\mathrm{T}_{1}$

where,

$\mathrm{G}_{1}=$ the $\mathrm{G}^{*} / \sin \delta$ value in $\mathrm{kPa}$ at a specific temperature $\mathrm{T}_{1}$ $\mathrm{a}=$ the slope of the stiffness-temperature curve determined as $\Delta \log \left(\mathrm{G}^{*} / \sin \delta\right) / \Delta \mathrm{T}$

3. Low critical temperature ( $\mathrm{Tc}(\mathrm{Low}))$. The slope of the stiffness-temperature curve of the RTFOT RAP binder is determined as $\Delta \log (\mathrm{S}) / \Delta \mathrm{T}$ and Equation 7 is used:

$$
\mathrm{T}_{\mathrm{C}}(\mathrm{Low})(\mathrm{S})=\left(\frac{\log (300)-\log \left(\mathrm{S}_{1}\right)}{\mathrm{a}}\right)+\mathrm{T}_{1}
$$

where,

$\mathrm{S}_{1}=$ the $\mathrm{S}$ value in MPa at a specific temperature $\mathrm{T}_{1}$ $\mathrm{a}=$ the slope of the stiffness-temperature curve determined as $\Delta \log (\mathrm{S}) / \Delta \mathrm{T}$

The slope of the stiffness-temperature curve of the RTFOT RAP binder is determined as $\Delta(\mathrm{m}) / \Delta \mathrm{T}$ and Equation 8 is used:

$$
\mathrm{T}_{\mathrm{C}}(\mathrm{Low})(\mathrm{m})=\left(\frac{0.300-\mathrm{m}_{1}}{\mathrm{a}}\right)+\mathrm{T}_{1}
$$

where,

$\mathrm{m}_{1}=$ the $\mathrm{m}$ value at a specific temperature $\mathrm{T}_{1}$

$\mathrm{a}=$ the slope of the stiffness-temperature curve determined as $\Delta(\mathrm{m}) / \Delta \mathrm{T}$

$T_{C}(L o w)$ is chosen between $T_{C}(L o w)(S)$ and $T_{C}(L o w)(m)$ as the most restrictive value (the higher one).

At this point, there are two methods to be followed depending on the available data for the mix design: RAP percentage of the mix or properties of virgin binder. In the first case, when the RAP content is known, an adequate virgin binder can be chosen in order to get a particular grade of the blend of the RAP binder and the new one by using Equation 9:

$$
T_{V B}=\frac{T_{B l e n d}-\left(\% R A P \times T_{R A P}\right)}{(1-\% R A P)}
$$

where,

$\mathrm{T}_{\text {blend }}=$ critical temperature of the final blend of binders

$\mathrm{T}_{\mathrm{RAP}}=$ critical temperature of the RAP binder

$\mathrm{T}_{\mathrm{VB}}=$ critical temperature of the virgin binder used as rejuvenator

$\%$ RAP $=$ percentage of RAP expressed as a decimal 
For the other case, when the virgin binder properties are known, the \%RAP can be determine as follows (Equation 10) to obtain the desired grade of the blend:

$$
\% R A P=\frac{T_{\text {blend }}-T_{V B}}{T_{R A P-T_{V B}}}
$$

where each term represents the same as above.

\section{AUS methodology:}

A recent report published by AUSTROADS (2013) describes a guideline for carrying out RAP binder blend design. Once the RAP binder has been recovered, they recommend determining the complex viscosity of the RAP, the virgin binder and the rejuvenator (if it is the case) in the DSR at $60^{\circ} \mathrm{C}$ and $1 \mathrm{rad} / \mathrm{s}$ according to AASHTO T315-12. Then, the viscosity of the blend can be predicted using the Chevron model with Equations 11-13:

$$
\begin{aligned}
& V B I_{i}=\frac{\log \vartheta_{i}}{3+\log \vartheta_{i}} \\
& V B I_{\beta}=\sum_{i=1}^{n} x_{i} V B I_{i} \\
& \mu=10^{\left(\frac{3 V B I_{\beta}}{1-V B I_{\beta}}\right)}
\end{aligned}
$$

where,

$\vartheta_{i}=$ viscosity of $\mathrm{i}^{\text {th }}$ component $(\mathrm{cP})$

$V B I_{i}=$ viscosity blending index of $\mathrm{i}^{\text {th }}$ component

$V B I_{\beta}=$ viscosity blending index of the blend

$x_{i}=$ volume fraction of $\mathrm{i}^{\text {th }}$ component

$\mu=$ viscosity of the blend (cP)

In this model it is assumed for the material under study that the percentages by volume are equal to percentages by weight (neglecting differences in density). Therefore, the prediction law would follow the expression in Equation 14:

$$
\mu^{1 / 3}=w_{A} \mu_{A}^{1 / 3}+w_{B} \mu_{B}^{1 / 3}
$$

where,

$\mu=$ viscosity of the blend (cP)

$\mu_{A}=$ viscosity of component $\mathrm{A}(\mathrm{cP})$

$\mu_{B}=$ viscosity of component $\mathrm{B}(\mathrm{cP})$

$w_{A}=$ weight fraction of component $\mathrm{A}(\mathrm{cP})$

$w_{B}=$ weight fraction of component $\mathrm{B}(\mathrm{cP})$ 


\section{Material and methods}

For the purpose of this research, hot and warm Stone Mastic Asphalt (SMA) mixtures were established as targets for the design of mixtures containing RAP. The selected virgin binder was a 50/70 penetration grade bitumen. In order to characterise this bitumen, penetration at $25^{\circ} \mathrm{C}$ (EN 1426:2007), softening point (EN 1427:2007), Fraass breaking point (EN 12593:2007) and rotational viscosity at $135^{\circ} \mathrm{C}$ (EN 13302:2010) tests were performed. These properties are shown in Table 1.

RAP was received from a long-aged source. RAP binder content was determined to be 5.8\% following the EN 12697-1:2012 and binder was recovered from the RAP following EN 12697-4:2005 Fractionating Column by distillation. Once it was recovered, the same experimental tests as those performed for the virgin binder were undertaken for the recovered RAP binder (RAPb) to characterise and compare their properties. Conventional properties of RAPb are shown in Table 1.

Table 1. Properties of 50/70 penetration grade bitumen and recovered binder from $R A P(R A P b)$

\begin{tabular}{ccccc}
\hline Bitumen & $\begin{array}{c}\text { Penetration } \\
@ 25^{\circ} \mathrm{C}(\mathrm{dmm})\end{array}$ & $\begin{array}{c}\text { Softening } \\
\text { point }\left({ }^{\circ} \mathrm{C}\right)\end{array}$ & $\begin{array}{c}\text { Rotational } \\
\text { viscosity @ } \\
135^{\circ} \mathrm{C}(\mathrm{mPa} . \mathrm{s})\end{array}$ & $\begin{array}{c}\text { Fraass } \\
\text { breaking } \\
\text { point }\left({ }^{\circ} \mathrm{C}\right)\end{array}$ \\
\hline $\begin{array}{c}50 / 70 \text { pen } \\
\text { grade }\end{array}$ & 68 & 47.6 & 273 & -8 \\
\hline $\begin{array}{c}\text { Recovered } \\
\text { binder } \\
(\mathrm{RAPb})\end{array}$ & 8.3 & 71.4 & 1827 & +8.7 \\
\hline
\end{tabular}

Three RAP contents (over the total weight of mix) were defined for the blend design: 30\% RAP, 60\% RAP and 90\% RAP. These RAP percentages were chosen after checking that the RAP gradation could meet the requirements for the manufacture of a SMA mixture with those RAP percentages.

In order to achieve high RAP contents, the virgin binder and two different rejuvenators were considered:

- Rejuvenator A (RejA) for the future manufacture of WMA

- Rejuvenator B (RejB) for the future manufacture of HMA

RejA is an additive whichconsists of a special regenerated oil and a FischerTropsch wax. The oil rejuvenates the bitumen of the reclaimed asphalt to a predetermined degree of softness, while the Fischer-Tropsch wax improves the mixability and workability of the asphalt in order to obtain a WMA. RejB is an additive characterized by having high viscosity and free of polycyclic aromatic hydrocarbons. 


\subsection{Binder blend design}

The aim of this phase is to predict the properties of the future Rejuvenated $\mathrm{RAPb}$ and virgin binder blends in order to assess whether they could be used to produce WMA and HMA.

The first step in carrying out the blend design was to define the ratio between the rejuvenators and the $\mathrm{RAPb}$ to obtain the Rejuvenated $\mathrm{RAPb}$. In this case, this additive/ $\mathrm{RAPb}$ ratio was selected following the instructions of the provider of the additives: $\mathrm{Rej} A / \mathrm{RAPb}=0.2$ and $\mathrm{Rej} \mathrm{B} / \mathrm{RAPb}=0.3$. On one hand, the calculation of RejB dosage aims to rejuvenate RAPb binder by decreasing its softening point to be closer to the virgin binder softening point. On the other hand, the addition of RejA would not change the softening point of the RAPb due to combined effect of waxes and oil, so the recommendation of its dosage was based on empirical experiences.

Blend design was performed following the European (EN 13108-8:2005), Australian (AUSTROADS 2013) and US (NCHRP Report 452 2001) recommendations. Therefore, RAPb, virgin binder and both Rejuvenated $\mathrm{RAPb}$ were tested according to the plan shown in Figure 1.

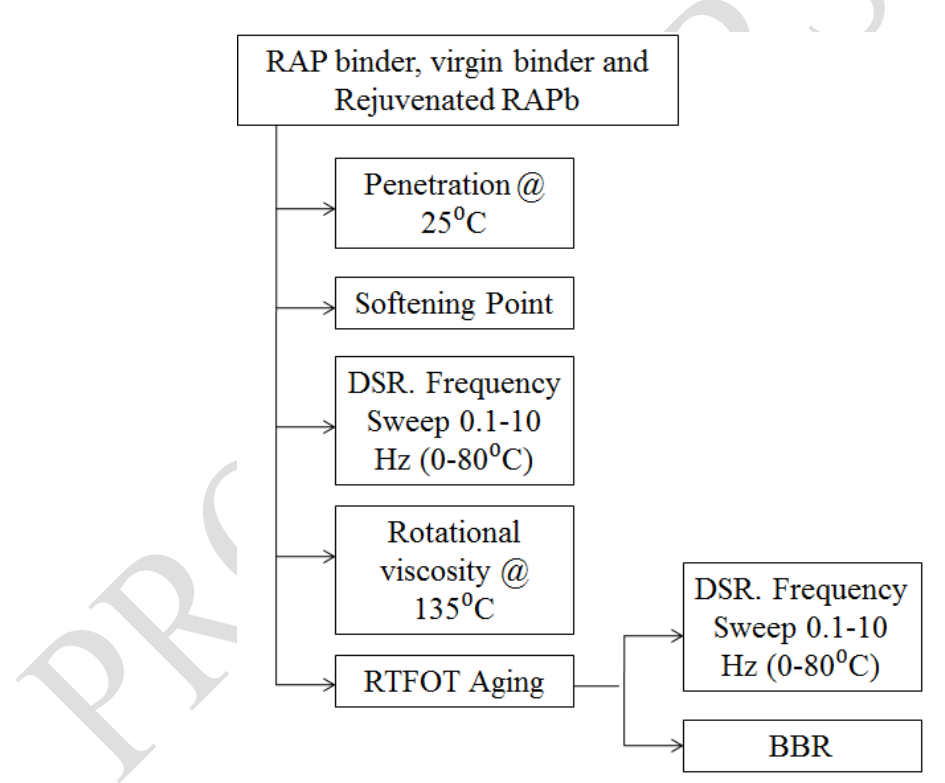

Figure 1. Testing plan for blend design

Once the testing plan was fulfilled, blending charts and blending laws were built. Blending charts are graphs in which the $\mathrm{x}$-axis represents the percentage of RAP in the asphalt mix from $0 \%$ to $100 \%$, while the y-axis represents the property under control of the binder. In this sense, the $0 \%$ RAP is the property of the virgin binder and the $100 \%$ is the property of the Rejuvenated RAPb which will be blended with the virgin binder (Figure 2). As reported in section 2, blending laws are the models internationally used to assess the property of the final blend depending on the 
dosage of each component (Equations 1, 2, 3 and 13). In this sense, blend design was performed for penetration at $25^{\circ} \mathrm{C}$, softening point, critical temperatures and complex viscosity at $60^{\circ} \mathrm{C}$. Having the blending laws, the desired RAP percentages are replaced in them and the value of each property of the final mix is obtained. Thus, it can be assessed whether the mixture is feasible or not depending on the binder properties.

One fact to be taken into account is that the RAP percentages to be replaced in the blending laws are not 30,60 and 90 but the real percentage of virgin binder that will be replaced by RAP and rejuvenator. This value is called Replaced Virgin Binder (RVB) and depends on five factors:

1. Final RAP content in the mix by weight: $30 \%, 60 \%$ and $90 \%$.

2. Binder content in the RAP: $5.8 \%$.

3. Percentage of blending between $\mathrm{RAPb}$ and virgin binder and additives. Given that the real percentage of blending that will occur on the mix is unknown, the possibility of 100, 80 and $60 \%$ of blending was considered. This initial assumption is based on previous researches that showed that for high RAP percentages high blending rates took place (Soleymani et al. 2000; Shirodkar et al. 2011; McDaniel et al. 2012).

4. Final content of binder in the mixture. Although the binder content in the mix was supposed to be $6.5 \%$, variations could occur. Therefore, the blend design was performed for $6,6.5$ and $7 \%$.

5. Rejuvenator content: $\mathrm{Rej} A / \mathrm{RAPb}=0.2$ and $\mathrm{Rej} \mathrm{B} / \mathrm{RAPb}=0.3$.

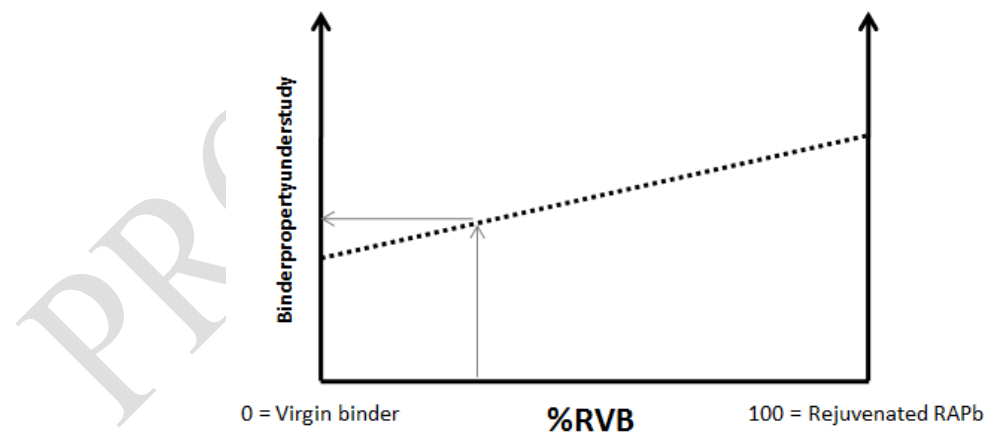

Figure 2. Example blending chart

Therefore, RVB (\%) is calculated following Equation 15:

$$
R V B(\%)=100 \cdot \frac{R A P \text { in the mixture } \cdot D O B \cdot R A P b \text { content } \cdot(1+R E J \text { ratio })}{\text { binder content in the mixture }}
$$


Where, RAP in the mixture is the total RAP percentage to add in the mixture by weight, DOB is the assumed degree of blending between RAP and virgin binders, $\mathrm{RAPb}$ content is the binder content in the RAP, REJ ratio is the ratio Rej/RAPb for each rejuvenator and binder content in the mixture is the designed final binder content in the mixture, being all the parameters expressed in decimals.

Table 3. Percentages of Replaced Virgin Binder (\%RVB) for the blend design for each rejuvenator

\begin{tabular}{|c|c|c|c|c|}
\hline Blending & $\%$ RAP & $\%$ Binder & $\% \mathrm{RVB}$ for RejA & $\% \mathrm{RVB}$ for RejB \\
\hline \multirow{3}{*}{$100 \%$} & \multirow{3}{*}{$30 \%$} & 6.0 & 34.8 & 37.7 \\
\hline & & 6.5 & 32.1 & 34.8 \\
\hline & & 7.0 & 29.8 & 32.3 \\
\hline \multirow{3}{*}{$80 \%$} & \multirow{3}{*}{$30 \%$} & 6.0 & 27.8 & 30.2 \\
\hline & & 6.5 & 25.7 & 27.8 \\
\hline & & 7.0 & 23.9 & 25.9 \\
\hline \multirow{3}{*}{$60 \%$} & \multirow{3}{*}{$30 \%$} & 6.0 & 20.9 & 22.6 \\
\hline & & 6.5 & 19.3 & 20.9 \\
\hline & & 7.0 & 17.9 & 19.4 \\
\hline \multirow{3}{*}{$100 \%$} & \multirow{3}{*}{$60 \%$} & 6.0 & 69.6 & 75.4 \\
\hline & & 6.5 & 64.2 & 69.6 \\
\hline & & 7.0 & 59.7 & 64.6 \\
\hline \multirow{3}{*}{$80 \%$} & \multirow{3}{*}{$60 \%$} & 6.0 & 55.7 & 60.3 \\
\hline & & 6.5 & 51.4 & 55.7 \\
\hline & & 7.0 & 47.7 & 51.7 \\
\hline \multirow{3}{*}{$60 \%$} & \multirow{3}{*}{$60 \%$} & 6.0 & 41.8 & 45.2 \\
\hline & & 6.5 & 38.5 & 41.8 \\
\hline & & 7.0 & 35.8 & 38.8 \\
\hline \multirow{3}{*}{$100 \%$} & & 6.0 & 104.4 & 113.1 \\
\hline & & 6.5 & 96.4 & 104.4 \\
\hline & & 7.0 & 89.5 & 96.9 \\
\hline \multirow{6}{*}{$60 \%$} & \multirow{3}{*}{$90 \%$} & 6.0 & 83.5 & 90.5 \\
\hline & & 6.5 & 77.1 & 83.5 \\
\hline & & 7.0 & 71.6 & 77.6 \\
\hline & \multirow{3}{*}{$90 \%$} & 6.0 & 62.6 & 67.9 \\
\hline & & 6.5 & 57.8 & 62.6 \\
\hline & & 7.0 & 53.7 & 58.2 \\
\hline
\end{tabular}

Taking into account these facts, the \%RVB were calculated for the different combinations, 27 for each rejuvenator. These values, shown in Table 3, will then be replaced in the blending laws to obtain the property of the final blends.

From Table 3, it can be observed that for mix with $90 \%$ RAP, the RVB percentage could be higher than $100 \%$ for both rejuvenators when full blending $(100 \%)$ is considered and binder content in the mix is $6 \%$. As a consequence, in these cases, $6 \%$ binder content is not high enough to achieve the desired rejuvenation effect for the selected RAP. Therefore, if the mix design will identify 
$6 \%$ as the optimum binder content, it will not be possible to obtain the desired rejuvenation level with the selected RejA and RejB. However, increasing the binder content to $6.5 \%$ for RejA and $7 \%$ for RejB, or assuming that partial blending would take place $(<80 \%)$, RVB percentages are again less than $100 \%$ and the mix manufacture would be feasible with both RejA and RejB and for all the three considered optimum binder contents.

\section{Results and discussion}

\subsection{Binder testing}

Table 4 shows the results of the conventional tests performed with the Rejuvenated $\mathrm{RAPb}$ for each rejuvenator. From the results, the softening effect that both rejuvenators exert in the RAP can be seen as compared to the initial properties. Both rejuvenators increased the penetration of the $\mathrm{RAPb}$. It has to be said that the penetration value of the Rejuvenated RAP binders are not reliable due to the nature of the rejuvenators, which after one hour in a test conditioning bath at $25^{\circ} \mathrm{C}$ showed signs of phase separation (Figure 3). Therefore, it was decided to obtain a predicted value of penetration at $25^{\circ} \mathrm{C}$ for Rejuvenated RAP binders from DSR testing data. Predicted values were calculated using Gershkoff equation (Gershkoff 1991) and are shown in Table 3. Since the difference between measured and predicted penetration was very notable, and the predicted values are more in accordance with the rest of test results, blend design was undertaken with both measured and predicted penetration data. Softening point of the Rejuvenated RAPb with RejB decreased almost $7^{\circ} \mathrm{C}$, while softening point of the Rejuvenated RAPb with RejA decreased $3^{\circ} \mathrm{C}$. It is also worth noting the remarkable reduction that the rejuvenators produce in the viscosity of the $\mathrm{RAPb}$ at $135^{\circ} \mathrm{C}$, which would significantly enhance the workability of the bituminous mixture, especially in the case of RejA (due to the waxes).

Table 5 shows the results of the BBR test of the virgin binder, RAPb and Rejuvenated RAP binders after RTFOT. Test temperatures were selected based on the DSR tests of the RTFOT samples. Results show the great improvement of the thermal cracking resistance of the Rejuvenated $\mathrm{RAPb}$ in comparison with the RAPb due to the effect of the rejuvenators.

After this testing, critical temperatures of all the binders were obtained according to NCHRP Report 452 (2001). Table 6 displays these results. They highlight the effect of both rejuvenators in the RAPb, which decreases the intermediate and low critical temperatures and maintains the high critical temperature. This effect implies that rejuvenators improve fatigue and thermal cracking resistance without affecting plastic deformation resistance. These results are in accordance with those showed by others authors (Tran et al. 2012). 
Binder design of high RAP content hot and warm asphalt mixture wearing courses 13

Table 4. Conventional properties of $R A P b$, Rejuvenated $R A P b$ and virgin binder

\begin{tabular}{cccccc}
\hline Binder & $\begin{array}{c}\text { Additive/ } \\
\mathrm{RAPb} \\
\text { Ratio }\end{array}$ & $\begin{array}{c}\text { Measured } \\
\text { Penetration @ } \\
25^{\circ} \mathrm{C}(\mathrm{dmm})\end{array}$ & $\begin{array}{c}\text { Predicted } \\
\text { Penetration @ } \\
25^{\circ} \mathrm{C}(\mathrm{dmm}) *\end{array}$ & $\begin{array}{c}\text { Softening } \\
\text { point } \\
\left({ }^{\circ} \mathrm{C}\right)\end{array}$ & $\begin{array}{c}\text { Rotational } \\
\text { viscosity @ } \\
135^{\circ} \mathrm{C}(\mathrm{mPa} . \mathrm{s})\end{array}$ \\
\cline { 2 - 6 } $\mathrm{RAPb}$ & - & 8.3 & - & 71.4 & 1827 \\
\hline $\begin{array}{c}\text { Rejuvenated } \\
\text { RAPb with RejA }\end{array}$ & 0.2 & 92 & 9.8 & 68.4 & 372.5 \\
\hline $\begin{array}{c}\text { Rejuvenated } \\
\text { RAPb with RejB }\end{array}$ & 0.3 & 120 & 11.9 & 65.7 & 1094 \\
\hline Virgin binder & - & 68 & - & 47.6 & 273 \\
\hline
\end{tabular}

*Predicted using Gershkoff equation: $\log \left(\mathrm{PEN} @ 25^{\circ} \mathrm{C}\right)=\left(-\log \left(\mathrm{G}^{*}\left(0.4 \mathrm{~Hz} @ 25^{\circ} \mathrm{C}\right)-8.8\right) / 1.95\right.$

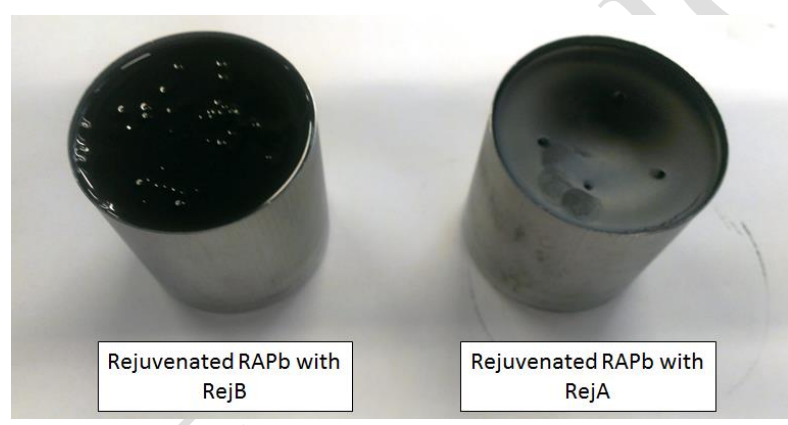

Figure 3. Rejuvenated $R A P b$ after penetration test

Table 5. BBR results

\begin{tabular}{cccc}
\hline Binder & \multicolumn{1}{c}{$\begin{array}{c}\text { Test temperature } \\
\left({ }^{\circ} \mathrm{C}\right)\end{array}$} & $\begin{array}{c}\text { Stiffness } \\
(\mathrm{MPa})\end{array}$ & $\begin{array}{c}\text { m- } \\
\text { value }\end{array}$ \\
\hline Virgin binder (after RTFOT) & -12 & 196.5 & 0.391 \\
\cline { 2 - 4 } RAPb (after RTFOT) & -18 & 459.5 & 0.294 \\
\cline { 2 - 5 } & -6 & 256 & 0.300 \\
\hline Rejuvenated RAPb with RejA (after RTFOT) & -12 & 503 & 0.237 \\
\cline { 2 - 5 } & -24 & 236 & 0.271 \\
\hline Rejuvenated RAPb with RejB (after RTFOT) & -30 & 394 & 0.209 \\
\cline { 2 - 5 } & -24 & 195 & 0.255 \\
\hline
\end{tabular}


Table 6. Virgin binder, $R A P b$ and Rejuvenated RAPb critical temperatures

\begin{tabular}{cccc}
\hline Binder & High $\left({ }^{\circ} \mathrm{C}\right)$ & Intermediate $\left({ }^{\circ} \mathrm{C}\right)$ & Low $\left({ }^{\circ} \mathrm{C}\right)$ \\
\cline { 2 - 4 } Virgin binder & 66 & 19 & -16 \\
\hline RAPb & 87 & 33 & -6 \\
\hline $\begin{array}{c}\text { Rejuvenated RAPb } \\
\text { with RejA }\end{array}$ & 71 & 11 & -21 \\
\hline $\begin{array}{c}\text { Rejuvenated RAPb } \\
\text { with RejB }\end{array}$ & 71 & 9.5 & -13 \\
\hline
\end{tabular}

\subsection{Blending charts and blend design results}

Blending charts and blending laws for the blend of Rejuvenated RAP binders with the virgin binder are shown in Figures 4, 5, 6, 7, 8 and 9. Tables 7 and 8 summarize the results of the blend design for RejA and RejB respectively showing the extreme values of each property for each percentage of RAP, while Table 9 displays the whole design for each RAP percentage, blending and binder content.

According to Tables 7 and 8, both final blends would be feasible for mixture production with every RAP percentage, even 90\%. With the exception of penetration values, studied properties show very convenient binders for WMA in the case of RejA, due to the low viscosity at high temperatures because of the presence of waxes; and HMA in the case of RejB.

In particular, critical temperatures reveal good performance of the binders to resist the most common distresses of pavements (rutting, fatigue and low temperature cracking).

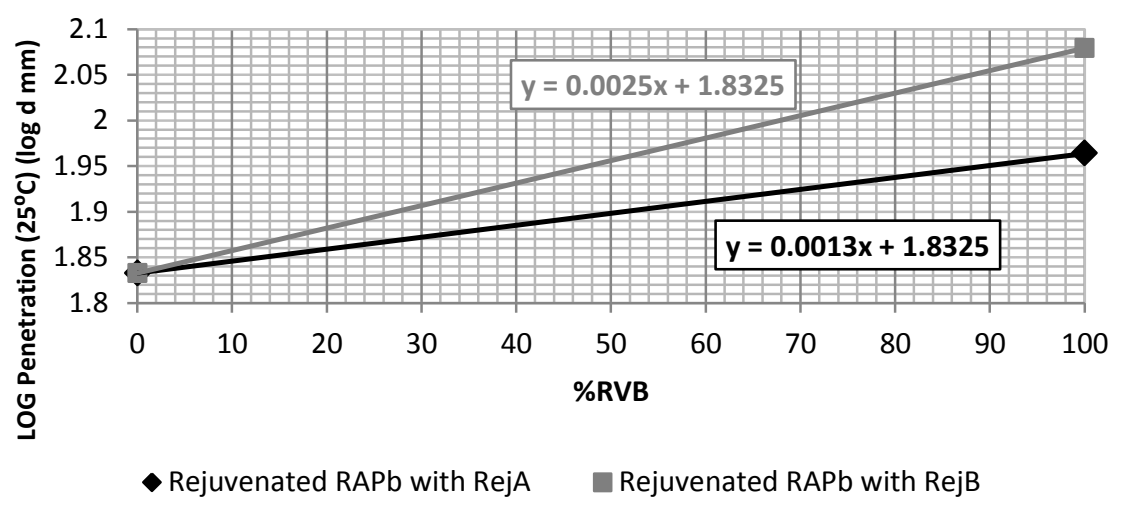

Figure 4. Blending chart and law for Penetration at $25^{\circ} \mathrm{C}$ with measured values 
Binder design of high RAP content hot and warm asphalt mixture wearing courses 15

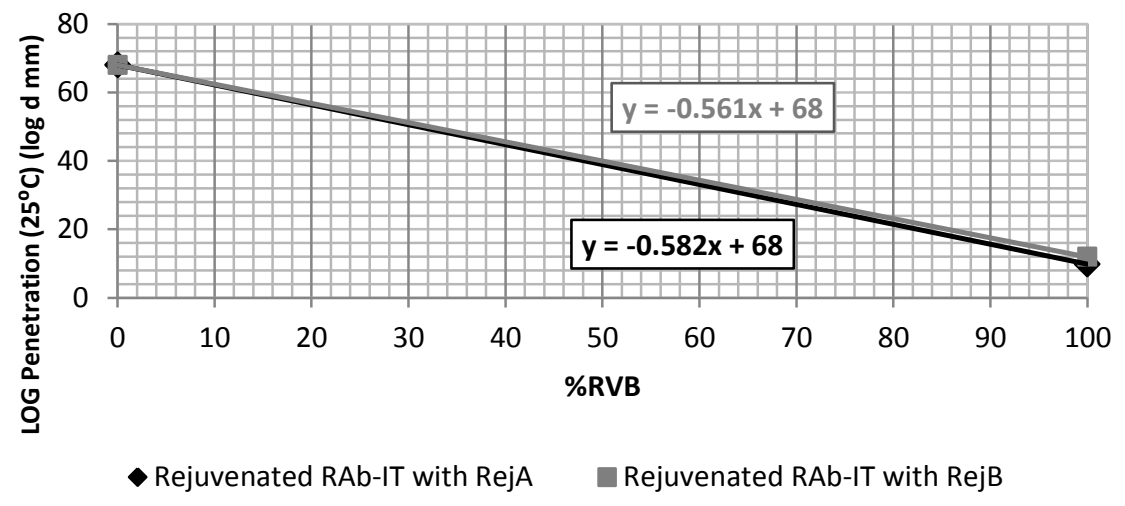

Figure 5. Blending chart and law for Penetration at $25^{\circ} \mathrm{C}$ with predicted values

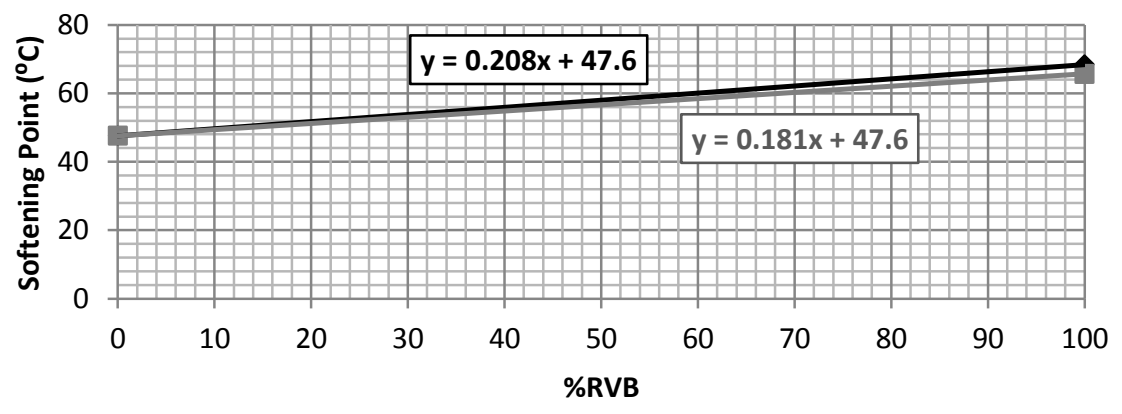

- Rejuvenated RAPb with RejA $\quad$ Rejuvenated RAPb with RejB

Figure 6. Blending chart and law for Softening Point

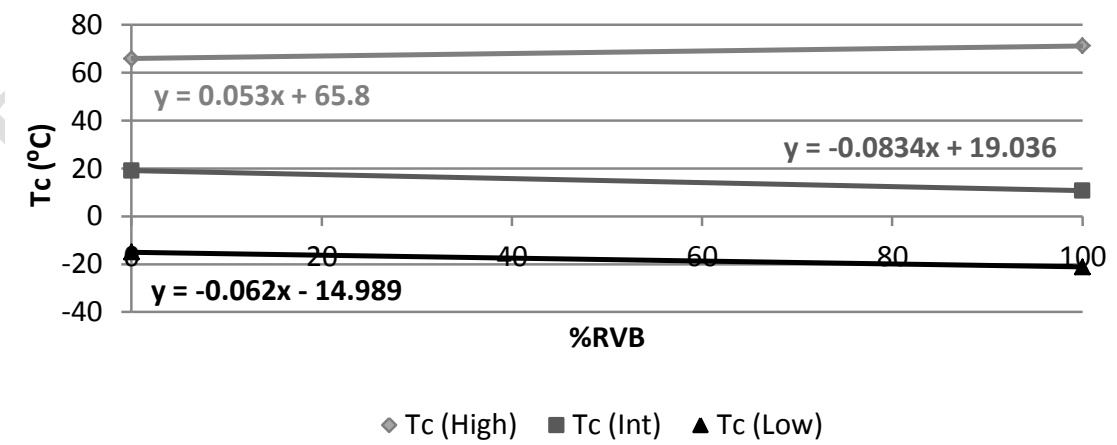

Figure 7. Blending chart and law for critical temperatures for virgin binder and rejuvenated $R A P b$ with RejA 


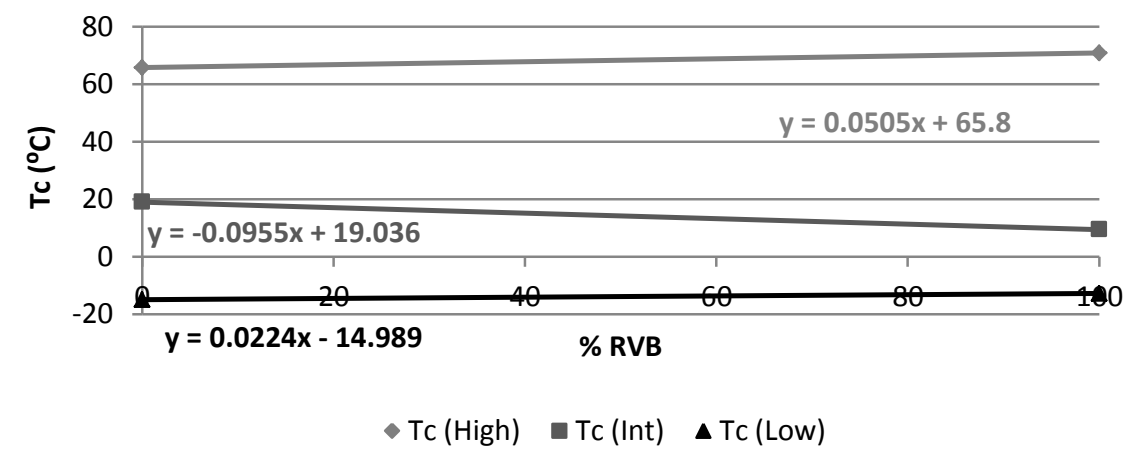

Figure 8. Blending chart and law for critical temperatures for virgin binder and rejuvenated $R A P b$ with $R e j B$

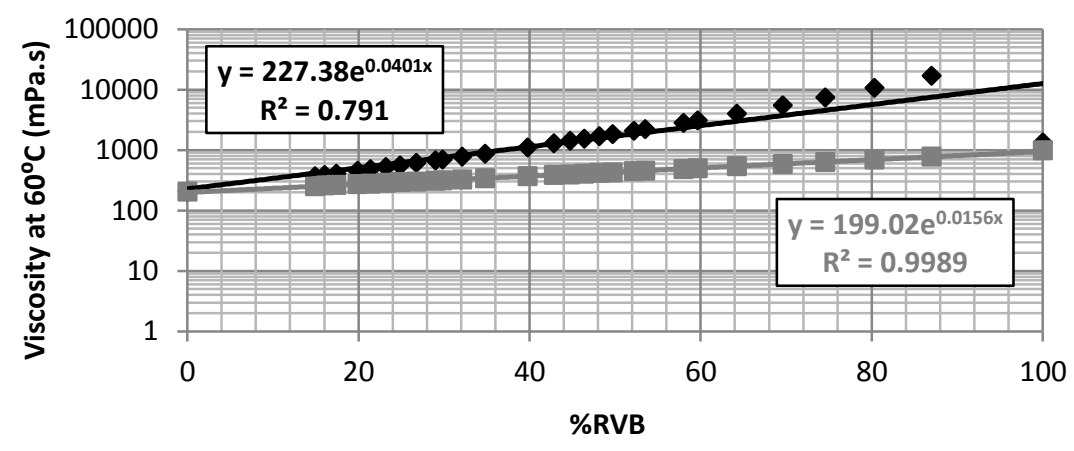

- Rejuvenated RAPb with RejA Rejuvenated RAPb with RejB

Figure 9. Blending chart and law for viscosity at $60^{\circ} \mathrm{C}$ (Chevron model)

Table 7. Summarized RejA blend design

\begin{tabular}{|c|c|c|c|c|c|c|c|c|}
\hline & & \multicolumn{7}{|c|}{ Final properties of blend with RejA } \\
\hline$\%$ RAP & & $\begin{array}{c}\text { Pen } 25^{\circ} \mathrm{C} \\
\text { using } \\
\text { measured } \\
\text { values }(\mathrm{dmm}) \\
\end{array}$ & $\begin{array}{c}\text { Pen } 25^{\circ} \mathrm{C} \\
\text { using } \\
\text { predicted } \\
\text { values }(\mathrm{dmm})\end{array}$ & $\begin{array}{l}\text { SP } \\
\left({ }^{\circ} \mathrm{C}\right)\end{array}$ & $\begin{array}{c}\text { Tc } \\
\text { (High) }\end{array}$ & $\begin{array}{c}\mathrm{Tc} \\
\text { (Int) }\end{array}$ & $\begin{array}{c}\text { Tc } \\
\text { (Low) }\end{array}$ & $\begin{array}{c}\text { Viscosity } \\
60^{\circ} \mathrm{C}\end{array}$ \\
\hline \multirow{2}{*}{$30 \%$} & Min. & 71.8 & 34.7 & 51.3 & 66.7 & 16.1 & -17.1 & 367.8 \\
\hline & Max. & 75.5 & 48.1 & 54.8 & 67.6 & 17.5 & -16.1 & 671.6 \\
\hline \multirow{2}{*}{$60 \%$} & Min. & 75.8 & 17.7 & 55.0 & 67.7 & 13.2 & -19.3 & 697.1 \\
\hline & Max. & 83.9 & 34.0 & 62.1 & 69.5 & 16.1 & -17.2 & 2825.5 \\
\hline \multirow{2}{*}{$90 \%$} & Min. & 80.0 & 9.0 & 58.8 & 68.6 & 11.0 & -21.0 & 1412.7 \\
\hline & Max. & 91.0 & 24.0 & 67.6 & 70.9 & 14.6 & -18.3 & 10718.9 \\
\hline
\end{tabular}


Binder design of high RAP content hot and warm asphalt mixture wearing courses 17

Table 8. Summarized RejB blend design

\begin{tabular}{|c|c|c|c|c|c|c|c|c|}
\hline & & \multicolumn{7}{|c|}{ Final properties of blend with RejB } \\
\hline \multicolumn{2}{|l|}{$\%$ RAP } & $\begin{array}{c}\text { Pen } 25^{\circ} \mathrm{C} \\
\text { using } \\
\text { measured } \\
\text { values }(\mathrm{dmm}) \\
\end{array}$ & $\begin{array}{c}\text { Pen } 25^{\circ} \mathrm{C} \\
\text { using } \\
\text { predicted } \\
\text { values }(\mathrm{dmm}) \\
\end{array}$ & $\begin{array}{l}\text { SP } \\
\left({ }^{\circ} \mathrm{C}\right)\end{array}$ & $\begin{array}{c}\text { Tc } \\
\text { (High) }\end{array}$ & $\begin{array}{c}\mathrm{Tc} \\
\text { (Int) }\end{array}$ & $\begin{array}{c}\text { Tc } \\
\text { (Low) }\end{array}$ & $\begin{array}{c}\text { Viscosity } \\
60^{\circ} \mathrm{C}\end{array}$ \\
\hline \multirow{2}{*}{$30 \%$} & Min. & 75.9 & 35.2 & 51.1 & 66.8 & 15.4 & -14.6 & 253.8 \\
\hline & Max. & 84.2 & 48.5 & 54.4 & 67.7 & 17.2 & -14.1 & 311.6 \\
\hline \multirow{2}{*}{$60 \%$} & Min. & 84.8 & 18.3 & 54.6 & 67.8 & 11.8 & -14.1 & 315.4 \\
\hline & Max. & 104.4 & 34.6 & 61.2 & 69.6 & 15.3 & -13.3 & 485.9 \\
\hline \multirow{2}{*}{$90 \%$} & Min. & 94.6 & 9.5 & 58.1 & 68.7 & 9.8 & -13.7 & 395.0 \\
\hline & Max. & 117.9 & 24.7 & 65.1 & 70.7 & 13.5 & -12.8 & 635.3 \\
\hline
\end{tabular}


Table 9. EU, USA and AUS blend design

\begin{tabular}{|c|c|c|c|c|c|c|c|c|c|c|c|c|c|c|c|c|c|c|}
\hline \multirow[b]{2}{*}{ Blending } & \multirow[b]{2}{*}{$\%$ RAP } & \multirow[b]{2}{*}{$\begin{array}{c}\% \\
\text { Binder }\end{array}$} & \multicolumn{8}{|c|}{ RejA } & \multicolumn{7}{|c|}{ RejB } & \multirow[b]{2}{*}{$\begin{array}{c}\text { Viscosity } \\
60^{\circ} \mathrm{C}\end{array}$} \\
\hline & & & $\begin{array}{c}\% \\
\text { RVB }\end{array}$ & $\begin{array}{c}\text { Pen } 25^{\circ} \mathrm{C} \\
\text { using } \\
\text { measured } \\
\text { values } \\
(\mathrm{dmm})\end{array}$ & $\begin{array}{c}\text { Pen } \\
25^{\circ} \mathrm{C} \\
\text { using } \\
\text { predicted } \\
\text { values } \\
(\mathrm{dmm}) \\
\end{array}$ & $\begin{array}{c}\text { SP } \\
\left({ }^{0} \mathrm{C}\right)\end{array}$ & $\begin{array}{c}\text { Tc } \\
\text { (High) }\end{array}$ & $\begin{array}{c}\mathrm{Tc} \\
\text { (Int) }\end{array}$ & $\begin{array}{c}\text { Tc } \\
\text { (Low) }\end{array}$ & $\begin{array}{c}\text { Viscosity } \\
60^{\circ} \mathrm{C}\end{array}$ & $\begin{array}{c}\% \\
\text { RVB }\end{array}$ & $\begin{array}{c}\text { Pen } 25^{\circ} \mathrm{C} \\
\text { using } \\
\text { measured } \\
\text { values } \\
(\mathrm{dmm})\end{array}$ & $\begin{array}{c}\text { Pen } \\
25^{\circ} \mathrm{C} \\
\text { using } \\
\text { predicted } \\
\text { values } \\
(\mathrm{dmm}) \\
\end{array}$ & $\begin{array}{c}\text { SP } \\
\left({ }^{0} \mathrm{C}\right)\end{array}$ & $\begin{array}{c}\text { Tc } \\
\text { (High) }\end{array}$ & $\begin{array}{c}\mathrm{Tc} \\
\text { (Int) }\end{array}$ & $\begin{array}{c}\text { Tc } \\
\text { (Low) }\end{array}$ & \\
\hline \multirow{3}{*}{$\begin{array}{c}100 \% \\
\text { Blending }\end{array}$} & \multirow{3}{*}{$30 \%$} & 6.0 & 34.8 & 75.5 & 34.7 & 54.8 & 67.6 & 16.1 & -17.1 & 671.6 & 37.7 & 84.2 & 35.2 & 54.4 & 67.7 & 15.4 & -14.1 & 311.6 \\
\hline & & 6.5 & 32.1 & 74.9 & 36.5 & 54.3 & 67.5 & 16.4 & -17.0 & 608.3 & 34.8 & 82.9 & 37.1 & 53.9 & 67.6 & 15.7 & -14.2 & 301.5 \\
\hline & & 7.0 & 29.8 & 74.4 & 38.2 & 53.8 & 67.4 & 16.6 & -16.8 & 559.4 & 32.3 & 81.7 & 38.7 & 53.4 & 67.4 & 16.0 & -14.3 & 293.1 \\
\hline \multirow{3}{*}{$\begin{array}{c}80 \% \\
\text { Blending }\end{array}$} & \multirow{3}{*}{$30 \%$} & 6.0 & 27.8 & 74.0 & 39.7 & 53.4 & 67.3 & 16.7 & -16.7 & 520.7 & 30.2 & 80.7 & 40.2 & 53.1 & 67.3 & 16.2 & -14.3 & 286.1 \\
\hline & & 6.5 & 25.7 & 73.5 & 41.3 & 52.9 & 67.2 & 16.9 & -16.6 & 482.4 & 27.8 & 79.6 & 41.9 & 52.6 & 67.2 & 16.4 & -14.4 & 278.8 \\
\hline & & 7.0 & 23.9 & 73.1 & 42.8 & 52.6 & 67.1 & 17.0 & -16.5 & 452.1 & 25.9 & 78.8 & 43.3 & 52.3 & 67.1 & 16.6 & -14.4 & 272.6 \\
\hline \multirow{3}{*}{$\begin{array}{c}60 \% \\
\text { Blending }\end{array}$} & \multirow{3}{*}{$30 \%$} & 6.0 & 20.9 & 72.4 & 45.4 & 51.9 & 66.9 & 17.3 & -16.3 & 407.5 & 22.6 & 77.3 & 45.8 & 51.7 & 66.9 & 16.9 & -14.5 & 263.0 \\
\hline & & 6.5 & 19.3 & 72.1 & 46.8 & 51.6 & 66.8 & 17.4 & -16.2 & 385.6 & 20.9 & 76.6 & 47.3 & 51.4 & 66.9 & 17.0 & -14.5 & 258.0 \\
\hline & & 7.0 & 17.9 & 71.8 & 48.1 & 51.3 & 66.7 & 17.5 & -16.1 & 367.8 & 19.4 & 75.9 & 48.5 & 51.1 & 66.8 & 17.2 & -14.6 & 253.8 \\
\hline \multirow{3}{*}{$\begin{array}{c}100 \% \\
\text { Blending }\end{array}$} & \multirow{3}{*}{$60 \%$} & 6.0 & 69.6 & 83.9 & 17.7 & 62.1 & 69.5 & 13.2 & -19.3 & 2825.5 & 75.4 & 104.4 & 18.3 & 61.2 & 69.6 & 11.8 & -13.3 & 485.9 \\
\hline & & 6.5 & 64.2 & 82.6 & 19.6 & 61.0 & 69.2 & 13.7 & -19.0 & 2221.0 & 69.6 & 101.0 & 20.2 & 60.2 & 69.3 & 12.4 & -13.4 & 452.9 \\
\hline & & 7.0 & 59.7 & 81.4 & 21.4 & 60.0 & 69.0 & 14.1 & -18.7 & 1818.0 & 64.6 & 98.2 & 22.0 & 59.3 & 69.1 & 12.9 & -13.5 & 426.6 \\
\hline \multirow{3}{*}{$\begin{array}{c}80 \% \\
\text { Blending }\end{array}$} & \multirow{3}{*}{$60 \%$} & 6.0 & 55.7 & 80.5 & 23.1 & 59.2 & 68.8 & 14.4 & -18.4 & 1535.1 & 60.3 & 95.8 & 23.8 & 58.5 & 68.8 & 13.3 & -13.6 & 405.3 \\
\hline & & 6.5 & 51.4 & 79.4 & 25.1 & 58.3 & 68.5 & 14.8 & -18.2 & 1285.1 & 55.7 & 93.3 & 25.8 & 57.7 & 68.6 & 13.7 & -13.7 & 383.6 \\
\hline & & 7.0 & 47.7 & 78.6 & 27.0 & 57.5 & 68.3 & 15.1 & -17.9 & 1107.3 & 51.7 & 91.2 & 27.6 & 57.0 & 68.4 & 14.1 & -13.8 & 366.2 \\
\hline $60 \%$ & $60 \%$ & 6.0 & 41.8 & 77.1 & 30.3 & 56.3 & 68.0 & 15.6 & -17.6 & 875.1 & 45.2 & 87.9 & 30.9 & 55.8 & 68.1 & 14.7 & -14.0 & 339.7 \\
\hline
\end{tabular}




\begin{tabular}{|c|c|c|c|c|c|c|c|c|c|c|c|c|c|c|c|c|c|c|}
\hline \multirow[t]{2}{*}{ Blending } & & 6.5 & 38.5 & 76.4 & 32.2 & 55.6 & 67.8 & 15.8 & -17.4 & 773.5 & 41.8 & 86.2 & 32.8 & 55.2 & 67.9 & 15.0 & -14.1 & 326.4 \\
\hline & & 7.0 & 35.8 & 75.8 & 34.0 & 55.0 & 67.7 & 16.1 & -17.2 & 697.1 & 38.8 & 84.8 & 34.6 & 54.6 & 67.8 & 15.3 & -14.1 & 315.4 \\
\hline \multirow{3}{*}{$\begin{array}{c}100 \% \\
\text { Blending }\end{array}$} & \multirow{3}{*}{$90 \%$} & 6.0 & 104.4 & - & 9.0 & - & - & - & - & - & 113.1 & & 9.5 & - & - & - & - & - \\
\hline & & 6.5 & 96.4 & 91.0 & 10.5 & 67.6 & 70.9 & 11.0 & -21.0 & 10718.9 & 104.4 & - & 11.0 & - & - & - & - & - \\
\hline & & 7.0 & 89.5 & 89.1 & 12.0 & 66.2 & 70.5 & 11.6 & -20.5 & 7439.5 & 96.9 & 117.9 & 12.6 & 65.1 & 70.7 & 9.8 & -12.8 & 635.3 \\
\hline \multirow{3}{*}{$\begin{array}{c}80 \% \\
\text { Blending }\end{array}$} & \multirow{3}{*}{$90 \%$} & 6.0 & 83.5 & 87.5 & 13.5 & 65.0 & 70.2 & 12.1 & -20.2 & 5492.4 & 90.5 & 113.7 & 14.0 & 64.0 & 70.4 & 10.4 & -13.0 & 585.5 \\
\hline & & 6.5 & 77.1 & 85.8 & 15.3 & 63.6 & 69.9 & 12.6 & -19.8 & 4012.2 & 83.5 & 109.3 & 15.9 & 62.7 & 70.0 & 11.1 & -13.1 & 536.9 \\
\hline & & 7.0 & 71.6 & 84.4 & 17.0 & 62.5 & 69.6 & 13.1 & -19.4 & 3096.1 & 77.6 & 105.6 & 17.6 & 61.6 & 69.7 & 11.6 & -13.3 & 498.8 \\
\hline \multirow{3}{*}{$\begin{array}{c}60 \% \\
\text { Blending }\end{array}$} & \multirow{3}{*}{$90 \%$} & 6.0 & 62.6 & 82.2 & 20.2 & 60.6 & 69.1 & 13.8 & -18.9 & 2069.4 & 67.9 & 100.0 & 20.8 & 59.9 & 69.2 & 12.6 & -13.5 & 443.5 \\
\hline & & 6.5 & 57.8 & 81.0 & 22.2 & 59.6 & 68.9 & 14.2 & -18.6 & 1680.6 & 62.6 & 97.1 & 22.8 & 58.9 & 69.0 & 13.1 & -13.6 & 416.6 \\
\hline & & 7.0 & 53.7 & 80.0 & 24.0 & 58.8 & 68.6 & 14.6 & -18.3 & 1412.7 & 58.2 & 94.6 & 24.7 & 58.1 & 68.7 & 13.5 & -13.7 & 395.0 \\
\hline
\end{tabular}




\section{Conclusions}

The research in this paper presents a methodology to assess the feasibility of using high RAP percentages in the manufacture of mixes, based on the design of blends with RAP binder, virgin binder and rejuvenators.

Firstly, from the international blend design review for binders with high RAP content, it can be concluded that each country considers different properties and models for the binders, which can lead to different binder designs.

From the work undertaken with RAP, virgin binder and rejuvenators, the following concluding remarks can be highlighted:

- American and Australian blend design models may successfully include the use of rejuvenators through the application of current laws to rejuvenated RAP binders and virgin binders. However, European model seems not adequate to include the use of rejuvenators due to phase separation issues found when testing rejuvenated RAP binders for penetration.

- Before undertaking blend design with virgin and Rejuvenated RAP binders, a right rejuvenator dosage has to be defined to obtain the desired rejuvenating effect on RAP binder.

- Replaced Virgin Binder percentages have to be calculated taking into account the real percentage of RAP binder and the amount of rejuvenator that will blend with the virgin binder in the mixture. This point is important to ensure that the mix design is feasible with the selected rejuvenators' ratios.

- Ratios of rejuvenators used have greatly modified RAP binder properties, improving its behaviour at intermediate and low temperatures while not affecting its good performance at high temperatures.

- The use of rejuvenators and development of careful blend design could allow the increase in RAP content in both hot and warm asphalt mixes up to $90 \%$.

Authors are aware that the increase of RAP content in mixtures depends on more factors (such as plant issues) and not only on binder properties. In this sense, the research presented is expected to be only a step forward to the accomplishment of high RAP content mixtures. In addition, it has to be considered that the percentage of RAP to be used in mixes is highly dependent on the properties of the initial RAP binder, virgin binder and rejuvenators, so every case has to be independently and carefully studied.

Further work will be carried out with both binders and mixes for validation of the present design. 


\section{Acknowledgements}

The authors would like to acknowledge Dr.Elie Hajj of University of Reno for the transfer of knowledge and feedback received; the technical personnel of Storimpex AsphalTec GmbH Storimpex for the constant support during the experimental programme; the coordination of the Allback2Pave project at Dresden University of Technology and the colleagues at Universita' degli studi di Palermo for providing materials and laboratory support. The research presented is carried out as part of the CEDR Transnational Road research Programme Call 2012(http://allback2pave.fehrl.org) and the Marie Curie Initial Training Network (ITN) action, FP7-PEOPLE-2013-ITN (http://www.superitn.eu). The funding for the research was provided by the national road administrations of Denmark, Finland, Germany, Ireland, Netherlands and Norway and European Union's Seventh Framework Programme for research, technological development and demonstration under grant agreement number 607524 .

\section{References}

AASHTO T315-12.(2012). Standard Method of Test for Determining the Rheological Properties of Asphalt Binder Using a Dynamic Shear Rheometer (DSR).American Association of State and Highway Transportation Officials

AUSTROADS (2013).TECHNICAL REPORT AP-T245-13.Maximising the Re-use of Reclaimed Asphalt Pavement: Binder Blend Characterisation. Austroads Ltd, Sydney, Australia.

Dony, A., Colin, J., Bruneau, D., Drouadaine, I., \& Navaro, J. (2013). Reclaimed asphalt concretes with high recycling rates: Changes in reclaimed binder properties according to rejuvenating agent. Construction and Building Materials, (41), 175-181.

EN 1426:2007. Bitumen and bituminous binders. Determination of needle penetration.

EN 1427:2007. Bitumen and bituminous binders. Determination of the softening point - Ring and ball method.

EN 12593:2007. Bitumen and bituminous binders. Determination of the Fraass breaking point.

EN 12697-1:2012 Bituminous Mixtures. Test methods for hot mix asphalt. Soluble binder content.

EN 12697-4:2005 Bituminous Mixtures. Test methods for hot mix asphalt. Binder recovery. Fractionating column

EN 13108-8:2005 Bituminous Mixtures. Materials Specifications. Part 8: Reclaimed Asphalt

EN 13302:2010 Bitumen and bituminous binders. Determination of dynamic viscosity of bituminous binder using a rotating spindle apparatus 
Gershkoff, J.C. (1991). "A Study of the Rheological Behaviour of Some Surface Dressing Binders", MSc Thesis, School of Civil Engineering, The University of Nottingham.

Hajj, E., Sebaaly, P. \& Shrestha, R. (2009). Laboratory Evaluation of Mixes Containing Recycled Asphalt Pavement (RAP). Road Materials and Pavement Design, 10(3), 495-517.

McDaniel, R., Shah, A., Huber, G.A. \& Copeland, A. (2012). Effects of reclaimed asphalt pavements content and virgin binder grade on properties of plant produced mixtures. Road Materials and Pavement Design, 13, 161-182.

Mollenhauer, K. (2010). "Synthesis of national and international documents on existing knowledge regarding the recycling of reclaimed road materials in asphalt" - Direct_Mat deliverable 5

NCHRP (2001a). Report 452 Recommended Use of Reclaimed Asphalt Pavement in the Superpave Mix Design Method: Technician's Manual. Transportation Research Board, National Research Council, National Academy Press, Washington D.C., USA.

Shirodkar, P., Mehta, Y., Nolan, A., Sonpal, K., Norton, A., Tomlinson, C., Dubois, E., Sullivan, P. \& Suaber, R.(2011). A study to determine the degree of partial blending of reclaimed asphalt pavement (RAP) binder for high RAP hot mix asphalt. Construction and Building Materials, 25(1), pp.150-155.

Soleymani, H.R., Anderson, M., McDaniel, R. \& Abdelrahman, M.(2000). Investigation of the Black Rock Issue for Recycled Asphalt Mixtures. Journal of the Association of Asphalt Pavement Technologists, 69, 366-390.

Shen, J., Amirkhanian, S., \& Aune Miller, J. (2007). Effects of Rejuvenating Agents on Superpave Mixtures Containing Reclaimed Asphalt Pavement. Journal of Materials in Civil Engineering, 19(5), 376-384.

Tran, N.H., Taylor, A. \& Willis, R. (2012). NCAT Report 12-05 Effect of rejuvenator on performance properties of HMA mixtures with high RAP and RAS contents. National Center for Asphalt Technology at Auburn University, June 2012.

Visintine, B., Khosla, N.P., Tayebali, A. (2013). Effect of higher percentage of recycled asphalt pavement on pavement performance. Road Materials and Pavement Design, 14:2, 432-437.

Zaumanis, M., Mallick, R. B. \& Frank, R. (2013). "Use of rejuvenators for production of sustainable high content RAP hot mix asphalt". XVIII International Baltic Road Conference, Vilnius, Lithuania, 26-28 August 2013.

Zaumanis, M., Mallick, R. B., \& Frank, R. (2014). Evaluation of different recycling agents for restoring aged asphalt binder and performance of $100 \%$ recycled asphalt. Materials and Structures. doi:10.1617/s11527-014-0332-5 